\title{
PERFORMANCE IMPROVEMENT BY TEMPERATURE CONTROL OF AN OPEN-CATHODE PEM FUEL CELL SYSTEM
}

\author{
S. Strahl ${ }^{1 * *}$, A. Husar ${ }^{1}$, P. Puleston ${ }^{2}$, J. Riera $^{1}$ \\ ${ }^{1}$ Institut de Robòtica i Informàtica Industrial (UPC/CSIC), C/ Llorens i Artigas 4, 08028 Barcelona, Spain \\ ${ }^{2}$ CONICET and LEICI, Facultad de Ingeniería, Universidad Nacional de La Plata, CC 91, (1900) La Plata, Argentina
}

[*] Corresponding author, sstrahl@iri.upc.edu

\begin{abstract}
The work presented in this article combines experimental analysis and theoretical studies of temperature effects on the performance of an open-cathode, self-humidified PEM fuel cell system for the design of optimal control strategies. The experimental analysis shows the great potential of improving the system performance by proper thermal management. The most significant temperature dependent parameter of the system under study is the exchange current density. On the one hand it is influenced positively by a temperature increase as this lowers the activation barrier. On the other hand a higher temperature causes a reduction of the electrochemical active sites in the cathode catalyst layer (CCL) due to lower water content in the ionomer and primary pores. Dynamic models for fuel cell temperature, liquid water transport and the related electrochemistry have been developed and validated against the experiment. A cascaded Extremum Seeking control algorithm with a local PI controller is proposed to regulate the temperature to a fuel cell voltage maximum. However, the slow dynamics of the temperature related catalyst-drying effect on performance complicate the optimal thermal management with model-free control strategies.
\end{abstract}

Keywords: PEMFC, Open-cathode, Temperature experiments, Catalyst performance modeling, Extremum Seeking Control

\section{INTRODUCTION}

PEM fuel cells provide advantages over other fuel cell technologies due to their high power densities and low operating temperatures. The low temperature allows for the use of low cost materials and less severe degradation because of smaller thermo-cycles. The fuel cell temperature has a strong effect on the water content in the ionomer of the membrane and the catalyst layers: Water diffusion through the membrane as well as the water uptake dynamics of the ionomer are strong functions of temperature as shown by the experiments of Strahl et al. [1] and Majsztrik et al. [2], respectively. The temperature effects on water transport in the catalyst layers are based on absorption and desorption of water into and from the ionomer, as well as evaporation and condensation in the pores of the catalyst layer. Water content in the catalyst layer has a direct effect on the electrochemical active surface area as analyzed by Wang et al. and Eikerling [3,4]. If water is evacuated from the primary (3-10 nm radius) and secondary (10-50 nm radius) pores of the catalyst layer, the protons may not reach the active sites for the electrochemical reaction with the reactant gases and the electrons, which is the key factor of PEM fuel cell performance.

The state of hydration of an open-cathode stack for backup power was investigated by Bidoggia et al. [5]. In their work they present an estimation of the hydration status of the membrane via Electrochemical Impedance Spectroscopy (EIS) techniques during standby for determining the cell's ability to perform a fast and safe start-up. In order to maintain proper catalyst layer humidification and thus guarantee optimal performance, proper fuel cell temperature control is essential. A higher temperature can reduce the stack performance and intensify the degradation of the membrane and the catalyst [6,7], while a lower temperature decreases the reaction kinetics and may also cause flooding due to lower water saturation pressures at lower temperatures, which is also a major concern from the water management perspective [8].

Fuel cell system modeling has played a decisive role in developing, optimizing and testing of fuel cell control strategies. However, modeling and controlling PEM fuel cell based systems is a particularly challenging task due to the interactions between physical phenomena of different nature and the presence of nonlinear structures [9]. The work presented by Riascos et al. [10] shows a first approach of how to control 
temperature of PEM fuel cells. Li et al. [11] proposed and studied robust variable structure control for the temperature control problem based on the dynamic thermal affine model.

Optimal thermal management related to humidification is a crucial issue in every PEM fuel cell based system. In this context, the use of external reactant gas humidification is intended to be avoided because the required humidifiers consume space and power, which decreases the overall system efficiency. Zhang et al. [12] experimentally demonstrated the strong effects of low humidity operation on fuel cell performance. However, there is still a lack of information on how to control the temperature of a fuel cell system that works without reactant humidification. The important links between temperature management and fundamental understanding of the catalyst layer humidification and activity have not sufficiently been explored.

This work presents an experimental analysis of temperature effects in an open-cathode, self-humidified PEM fuel cell system and the resulting dynamic thermal, water transport and electrochemistry models. Finally, simulation and experimental results are used to discuss possible control strategies based on Extremum Seeking algorithms for performance improvement via proper temperature control.

\section{EXPERIMENTAL ANALYSIS}

\subsection{Experimental setup}

The system under observation in this work is the commercially available $100 \mathrm{~W}, 20$ cell PEM fuel cell stack H-100 from Horizon Fuel Cells Technologies. This open-cathode system with an active area of $22.5 \mathrm{~cm}^{2}$ is self-humidified and air-cooled. It includes a single cooling fan directly attached to the fuel cell housing, which removes heat from the stack by forced convection and at the same time provides oxygen to the cathode. Thus, the cathode air supply and the stack cooling cannot be decoupled.

Figure 1 shows a schematic of the fuel cell system installed in a laboratory test station. The fan is powered separately by an external $12 \mathrm{~V}$ power supply. A fan controller provides the Pulse-Width-Modulation (PWM) duty cycle signal, which sets the fan velocity. The cathode inlet air velocity is measured in the fuel cell stack housing structure inside the environmental chamber by the high accuracy air flow sensor E75 from E+E Elektronik. The anode inlet is supplied with dry hydrogen and the outlet features a normally-closed electromagnetic valve for dead-ended operation and periodic purging, as shown in Figure 1. A manual forward pressure regulator maintains the anode inlet pressure at about 0.4 bar. This system by default operates in a constant purge period mode with a $500 \mathrm{~ms}$ purge duration and an interval of $10 \mathrm{~s}$. These settings can be modified in the test station setup. For testing under different ambient conditions, the stack is installed in an environmental chamber with the capability of controlling relative humidity, temperature and oxygen concentration of the ambient air. The average temperature of the 20 bipolar plate temperature measurements represents the fuel cell stack temperature in this work.

\subsection{Flow rate and temperature mapping experiment}

In order to check the applicability of performance optimization techniques via temperature control, the steady-state input-output transfer characteristics of the fuel cell system were identified experimentally. The input of the system is the PWM duty cycle of the cathode cooling fan, and the output is the stack voltage. At a constant current density the PWM duty cycle was decreased stepwise starting at $100 \%$ for higher current densities and $80 \%$ for lower current densities. The operating range of the fan is limited from $50 \%$ to $100 \%$ duty cycle due to the detent torque of the fan. Lower duty cycles would lead to stalling of the fan. For this experiment the ambient temperature and relative humidity were kept constant by the environmental chamber $\left(T_{a m b}=25^{\circ} \mathrm{C}, R H_{a m b}=75 \%\right)$.

\subsection{Discussion of experimental results}

As explained in section 2.1, the fan flow rate affects the stack temperature and the cathode stoichiometry. Eq. (1) relates the cathode stoichiometry to load current $I$ and the cathode inlet air velocity $v_{\text {air }}$. $A_{\text {inlet }}$ is the crosssectional area of the inlet manifold and $n_{\text {cell }}$ is the number of cells in the stack. $\rho_{\text {air }}$ and $M_{\text {air }}$ are the ambient air density and molar mass at $25^{\circ} \mathrm{C}$, respectively. The relation between the PWM duty cycle set point and the cathode inlet air velocity was determined experimentally, as shown in Figure 2. A third order polynomial of the PWM duty cycle matches the measured cathode inlet air velocity. 
$v_{\text {cat }}=\frac{\dot{n}_{\text {in }}^{O 2}}{\dot{n}_{\text {cons }}^{O 2}}=\frac{0.21 \frac{\rho_{\text {air }} A_{\text {inlet }} v_{\text {air }}}{M_{\text {air }}}}{n_{\text {cell }} \frac{I}{4 F}}$

The characteristic curves of stationary operation points were recorded in the linear region of the polarization curve for current densities from 0.09 to $0.27 \mathrm{~A} \mathrm{~cm}^{-2}$, as shown in Figure 3(a). Figure 3(b) shows the same experiment, but with the stack temperature as the x-coordinate, which is directly influenced by the fan flow rate. According to Eq. (1) and Figure 2, even the minimum cathode flow rate at $50 \%$ PWM duty cycle guarantees a stoichiometry of about 20 at the rated electrical power of $100 \mathrm{~W} / 8.3 \mathrm{~A}$. Thus, the stoichiometric effect of changes in the flow rate is negligible, whereas the effect on performance is caused by the change in the stack temperature, plotted in Figure 3(b).

The curves in Figure 3 clearly show that a voltage maximum exists at low cathode flow rates for each current density. Especially at the higher current densities a significant system performance gain can be obtained by regulating temperature at the optimal values due to improved reaction kinetics at higher temperatures [13]. These optimal temperature values are higher than the default values set by system's standard controller, which tries to maintain the stack temperature between 30 and $45{ }^{\circ} \mathrm{C}$ at standard operating conditions, depending on the stack current. For instance, at $0.18 \mathrm{~A} \mathrm{~cm}^{-2}$ a stack power gain of $2 \%$ is reached by increasing the temperature from the standard set point of 39 to $46^{\circ} \mathrm{C}$. In turn, the power consumption of the fan is reduced by $14 \%$, which equals $2 \%$ of the stack power at this operation point. Thus, the total performance improvement of the system by optimizing the temperature set point is $4 \%$ of the stack power.

As shown in Figure 3(b), a further increase in temperature beyond the voltage maximum leads to a severe voltage loss. The elevated temperature intensifies the drying of the catalyst layer. Since the electrolyte material in the catalyst layer requires the presence of water for the $\mathrm{H}+$ ions to reach the so-called threephase-contacts between reactant gas, electrolyte, and electrode catalyst [14], the decreasing water concentration during operation at elevated temperatures results in the loss of active sites and thus in an overall voltage decrease. The temperature effects on water content of the catalyst layer are discussed in more detail in section 3.2.

The dynamics of this phenomenon at $0.18 \mathrm{~A} \mathrm{~cm}^{-2}$ are shown in Figure 4. The spikes in the voltage signal result from periodic anode purges that were performed every $30 \mathrm{~s}$. In this experiment the PWM duty cycle was decreased stepwise from $62 \%$ to $51 \%$ and increased afterwards back to $64 \%$, as depicted in Figure 5(a). As stated above, the voltage increases with increasing temperature. However, at about $50{ }^{\circ} \mathrm{C}$ the characteristic voltage response changes. Even though the voltage still increases at the beginning of a step, it does not stabilize but keeps decreasing with time due to the drying effect. Increasing the temperature even more leads to a more severe voltage decline rate, as shown in Figure 4(a). These unstable points are marked in red in Figure 5, whereas the assumed stationary points where the voltage could stabilize are marked in green. From the control point of view the unstable region represents a challenging problem: After an increase in temperature the fuel cell reacts positively first, which means a performance improvement can be detected. However, no stable equilibrium is reached since the voltage keeps dropping and the performance ends up being worse than at the initial condition.

Decreasing the temperature stepwise afterwards leads to a similar characteristic voltage response, as depicted in Figure 4(b). The overall voltage trend is positive and leads to improved performance, however at the beginning of a step in the duty cycle the voltage first drops and then recovers. The reason is the same as above. The decrease in temperature causes the voltage to drop at the beginning due to reduced reaction kinetics. However, because of better humidification of the catalyst layer due to lower evaporation rates the steady-state performance increases. At lower temperatures the effect on reaction kinetics overbalances the humidification effect, because of the increased water content in the catalyst layer.

Figure 5 shows the experiment trajectory of the stack voltage as a function of PWM duty cycle and stack temperature. The plots depict that the system shows hysteresis, but the maximum exists in both directions and is located at the same PWM duty cycle set point.

Finally, the experimental analysis shows a major drawback for optimization strategies, which are the slow dynamics of the system. In Figure 4, interpreting the system as piecewise linear, the time constant of the voltage response after a step in PWM duty cycle is between 2 and 3 min, depending on the operation point. However, reaching steady-state may take more than $30 \mathrm{~min}$. Moreover, after passing the maximum the system becomes unstable and the voltage keeps decreasing linearly within the allowed operating range while the temperature increases due to the loss of efficiency. At last, a non-minimum phase effect ("wrong way effect") appears while returning to stable operation by decreasing the temperature, shown in Figure 4(b) at 
17:12, for instance. To provide a better understanding of the involved phenomena and their different dynamics, mathematical models for the observed temperature and voltage evolutions are explained in the following section.

\section{MODELING APPROACH}

In order to develop efficient control strategies a good dynamic model facilitates the design process and saves testing time and costs. This section provides the necessary physical and mathematical background for proper dynamic modeling. All modeling parameters are summarized in Table 1.

\subsection{Thermal model}

Regarding the fuel cell stack as a heated solid block, the total heat transfer rate $\dot{Q}_{f c}$ can be expressed as:

$$
\dot{Q}_{f c}=m_{f c} C_{p, f c} \frac{d T_{f c}}{d t}=\dot{Q}_{t o t}-\dot{Q}_{c o o l}-\dot{Q}_{\text {loss }}
$$

The stack's mass $m_{f c}$ and specific heat capacity $C_{p, f c}$ have been determined experimentally, as published earlier in [1]. Since the stack is air cooled, heat is removed by forced and natural convection. Thus, the overall heat transfer rate can be described by the sum of the heat sources and sinks. The second right hand side of Eq. (2) represents the total rate of heat generation minus the heat removal rate by forced convection and the uncontrolled heat loss due to natural convection from the fuel cell surface to the surroundings. Several thermal analyses and models of non-insulated PEM fuel cells e.g. by Müller and Stefanopoulou [15] have shown that the heat loss to the environment by natural convection and radiation is around $10 \%$ of the total waste heat. Since the studied fuel cell stack in this work is encased in a plastic support structure, it is assumed that the heat loss to the environment $\dot{Q}_{\text {loss }}$ is minimal and thus neglected. Therefore, only heat removal from the system by convective heat transport is considered.

The total rate of heat generation $\dot{Q}_{t o t}$ is given by the difference between the theoretical available power arising from the higher heating value (HHV) of hydrogen $P_{H 2}$ and the actual electrical power output $P_{e l}$. The free energy of the reaction can be transformed into a theoretical potential $E_{t h}$ via the Nernst equation. The HHV is used in this study because product water of the electrochemical reaction is assumed to be in the liquid state. Hence, the temperature change of the stack over time as a function of generated and removed heat can be described with the following set of equations:

$$
\begin{array}{ll}
\dot{Q}_{\text {tot }}=P_{H 2}-P_{e l}=I\left(E_{t h} n_{\text {cell }}-V_{\text {stack }}\right) & {[\mathrm{W}]} \\
\dot{Q}_{c o o l}=\rho_{\text {air }} A_{\text {inlet }} v_{\text {air }} C_{p, \text { air }}\left(T_{f c}-T_{a m b}\right) & {[\mathrm{W}]} \\
\frac{d T_{f c}}{d t}=\frac{1}{m_{f c} C_{p, f c}}\left(\dot{Q}_{t o t}-\dot{Q}_{c o o l}\right) & {\left[\mathrm{K} \mathrm{s}^{-1}\right]}
\end{array}
$$

Eq. (4) describes the heat removal by the cooling fan as a function of the ambient air density $\rho_{\text {air }}$, temperature $T_{a m b}$, heat capacity $C_{p, a i r}$, inlet velocity $v_{\text {air }}$ and cross-sectional area $A_{\text {inlet }}$ of the inlet manifold. The fan dynamic is modeled by a first-order linear time-invariant (LTI) system with an experimental determined time constant of approximately $1 \mathrm{~s}$. For the gain of the fan, which relates the PWM set point to the cathode inlet velocity, an experimentally determined polynomial fit is used, as explained in section 2.3. Since the time constant of the fan is two orders of magnitude faster than the thermal time constant, its dynamics can be neglected. The model was validated against experimental data from laboratory tests with the studied fuel cell stack, which is discussed in section 3.3.

\subsection{Liquid water transport model}

The experiments discussed in section 2 have shown the importance of proper humidification of the cathode catalyst layer (CCL). Thus, this second part of the model focuses on the variation of liquid water content in the CCL. In order to guarantee good proton conductivity of the catalyst layer water has to be present in the liquid state filling the primary pores or absorbed in the ionomer that covers the secondary pores $[3,4]$. In the primary pores liquid water provides a path for proton conduction to Pt particles that are not in direct contact 
with the ionomer. The work of Wang et al. [3] shows that Pt utilization in liquid water-filled pores is comparable to ionomer filled pores, which underlies the strong effects of liquid water content in the CCL on performance. The parameter that describes the liquid water content in this work is the liquid water saturation $s$, which is the ratio of the liquid volume to the total volume of void space in the porous structure [16]. Eq. (6) shows the mass flux balance of the CCL for the calculation of liquid water saturation variation over time:

$$
K_{S} \frac{d s}{d t}=J_{\text {gen }}-J_{\text {evap }}-J_{\text {diff }} \quad\left[\mathrm{kg} \mathrm{m}^{-2} \mathrm{~s}^{-1}\right]
$$

The right hand side of Eq. (6) represents the source of liquid water generated in the electrochemical reaction minus the liquid water loss due to evaporation and diffusion towards the channel. $K_{s}$ is the liquid water accumulation time constant. Water generation is described by Faraday's law which links current density to the production rate of the electrochemical reaction:

$$
J_{g e n}=\frac{I}{2 F A_{g e o}} M_{H_{2} O} \quad\left[\mathrm{~kg} \mathrm{~m}^{-2} \mathrm{~s}^{-1}\right]
$$

The work of Eikerling [4] has shown that evaporation rates in the CCL may be in the same order of magnitude as water production rates, depending on pore size and temperature. Eq. (8) describes the evaporative water flux as a function of vapor pressure $p^{v}$ and the temperature dependent saturated vapor pressure $p^{\text {sat }}$ in a similar approach as presented by $\mathrm{Wu}$ et al. [17]:

$$
\begin{aligned}
& J_{\text {evap }}=K_{\text {evap }} s \frac{M_{\mathrm{H}_{2} \mathrm{O}}}{R T A_{\text {pore }}}\left(p^{\text {sat }}-p^{v}\right) \text { if } p^{v}<p^{\text {sat }} \quad\left[\mathrm{kg} \mathrm{m}^{-2} \mathrm{~s}^{-1}\right] \\
& p^{\text {sat }}=p^{0} e^{\left(\frac{-E_{a}}{k_{B} T_{f c}}\right)} \quad[\mathrm{Pa}]
\end{aligned}
$$

In Eq. (8), $A_{\text {pore }}$ is the pore surface area per unit volume of the GDL/CL and $K_{\text {evap }}$ is the evaporation time constant. $E_{a}$ is the activation energy of evaporation and $p^{0}$ is the pre-exponential factor for a temperature range of $0-100{ }^{\circ} \mathrm{C}$ [4]. Due to the nature of open cathode systems plus the absence of reactant gas humidification, condensation does not occur since the vapor pressure does not exceed the saturated vapor pressure under the studied operation conditions. Another effect of low humidity operation is that variations of the local vapor pressure due to liquid water evaporation and diffusion through the GDL are negligible, compared to the temperature dominated absolute difference between saturated and local vapor pressure.

Water evacuates from the CCL by evaporation and liquid water diffusion through the porous diffusion media towards the channel. The common two-phase flow modeling approach that combines capillary theory with Darcy's law $[16,17]$ is used in this work for calculation of the diffusive liquid water flux:

$$
\begin{aligned}
& J_{\text {diff }}=K_{\text {diff }} \frac{s_{C L}-s_{c h}}{d_{\text {diff }}} \quad\left[\mathrm{kg} \mathrm{m}^{-2} \mathrm{~s}^{-1}\right] \\
& K_{\text {diff }}=\sigma \cos \Theta \sqrt{\epsilon_{\text {eff }} K_{\text {eff }}} \frac{k_{r l} \rho_{l}}{\mu_{l}} \mathfrak{J}(s)
\end{aligned}
$$

$K_{\text {eff }}$ is the effective permeability and $\epsilon_{\text {eff }}$ the effective porosity of the diffusion media. Effective values are applied since these material properties change from the CCL over the micro-porous layer (MPL) to the GDL. $\rho_{l}$ and $\mu_{l}$ are the density and viscosity of liquid water, respectively. $\sigma$ is the surface tension of liquid water and $\Theta$ is the effective contact angle of the diffusion media. Since the presented model is based on ordinary differential equation without spatial resolution, a simple linear relation between the liquid water saturation in the CCL $s_{C L}$ and the channel $s_{c h}$ across the thickness of the diffusion media $d_{d i f f}$ determines the diffusive liquid water flux. Due to the high cathode flow rates and the low humidity operation of the open cathode system no droplet formation can be observed in the cathode channels. Therefore the liquid water saturation at the GDL/channel interface $s_{c h}$ is set to 0 .

The net flux of liquid water through the CCL/membrane interface is set to 0 for this study. This is a fairly good assumption, especially at low current densities, concerning that Electroosmotic drag from anode to cathode is in the same order of magnitude as back-diffusion from cathode to anode [18]. Even at the high 
cathode stoichiometry this is a good assumption as shown in the water transport characterization experiments with the studied open-cathode stack by Strahl et al. [1].

The relation between liquid water saturation and capillary pressure is described by the common Leverette function $\mathfrak{I}(s)$ [16]. A cubic function of the liquid water saturation is used to calculate the relative permeability $k_{r l}$.

Finally, the liquid water accumulation constant $K_{s}$ has to include the effect of sorption and desorption into and from the ionomer in the catalyst layer. As explained by $\mathrm{Wu}$ et al. [17] the limiting dynamic for water removal from the CCL is rather desorption than evaporation because the time constant for desorption $K_{\text {sorp }}$ is several orders of magnitude lower.

$K_{S}=\epsilon_{e f f} \frac{V_{C L}}{A_{g e o}} \rho_{l} K_{\text {sorp }} \quad\left[\mathrm{kg} \mathrm{m}^{-2}\right]$

With the presented set of equation the liquid water content in the CCL can be calculated dynamically as a function of ambient conditions and fuel cell temperature.

\subsection{Electrochemical model}

The cell voltage of a PEM fuel cell $V_{f c}$ can be expressed as the thermodynamic reversible potential $E_{t h}$ minus the three major voltage losses: activation polarization $\eta_{a c t}$, ohmic $\eta_{o h m}$ and mass transport $\eta_{m t}$.

$V_{f c}=E_{t h}-\eta_{a c t}-\eta_{o h m}-\eta_{m t} \quad[\mathrm{~V}]$

Since every component of Eq. (13) is dependent on temperature, the effects have to be separated in order to determine the phenomena that are responsible for the temperature related observations in the experiments. Firstly, the thermodynamic reversible potential is defined by the Nernst equation as a function of Gibbs free energy, temperature and pressure and decreases linearly with temperature [13]. However, in the operating range of the system under study between 30 and $60^{\circ} \mathrm{C}$ this temperature effect is negligible.

The mass transport losses decrease with increasing temperature since the limiting current density is a function of the reactant diffusivity, which in turn is a strong function of temperature [13]. The temperature related phenomena shown in section 2 are all observed in the linear region of the polarization curve at current densities much smaller than the limiting current density. Hence, the temperature dependency of the mass transport losses does not affect the voltage response under these specific conditions. Possible changes in the concentration gradient along the reactant flow channels are compensated by operation at high reactant stoichiometries $\left(\boldsymbol{v}_{\text {an }}>2, \boldsymbol{v}_{\text {cat }}>20\right)$. Thus, the mass transport losses can be neglected in this work.

The ohmic losses depend on the ionic conductivity of the membrane, which increases linearly with increasing water content and exponentially with temperature [19]. Temperature and water content are strongly related since the membrane water content depends on the water saturation pressure, which in turn is a function of temperature. Hence, there is a tradeoff between increasing temperature and water content in order to optimize ionic conductivity. However, as shown in experiments of Ciureanu [20] and Husar et al. [21], the change in the ohmic losses due to temperature is only responsible for a relatively small part of the voltage increase/decay that is shown in section 2.

Thus, the major part is related to changes in the activation polarization losses. Eq. (14) describes these losses using a Tafel approach [13]:

$\eta_{a c t}=\frac{R T_{f c}}{\alpha n F} \ln \left(\frac{i}{i_{0}^{A E C D}}\right) \quad[\mathrm{V}]$

The activation polarization losses feature two different temperature dependencies. On one hand, as shown in Eq. (14), these losses increase linearly with temperature, but on the other hand, the apparent exchange current density $i_{0}^{A E C D}$ increases exponentially with temperature, as described by Eq. (15). $i_{0}^{A E C D}$ combines the intrinsic catalytic activity of the Pt catalyst at reference conditions $\left(T_{r e f}\right.$ and $\left.P_{r e f}\right) i_{0}^{r e f}$ with the catalyst layer morphology, fuel cell temperature and partial pressure of the reactants [12,22]. The real active area is described by the product of the specific catalyst area $a_{c}$ and the Pt loading $L_{c}$, which is equal to the ratio of the catalyst surface area per geometric area. $\Delta G^{*}$ is the energy of the activation barrier for the oxygen reduction reaction (ORR). 
$i_{0}^{A E C D}=i_{0}^{r e f} a_{c} L_{c}\left(\frac{p_{O 2}}{P_{r e f}}\right)^{0.5} e^{\left[-\frac{\Delta G^{*}}{R T_{f c}}\left(1-\frac{T_{f c}}{T_{r e f}}\right)\right]} \quad\left[\mathrm{A} \mathrm{m}{ }^{-2}\right]$

The physical reason for the positive temperature effect is that the increasing available thermal energy in the system increases the likelihood that a given reactant will possess sufficient energy to reach the activated state [13]. Incorporation of Eq. (15) into Eq. (14) and lumping all non-temperature dependent parameters into one constant $K_{i 0}$ allows for analyzing the temperature effects on the fuel cell current density:

$i=K_{i 0} e^{\left(-\frac{\Delta G^{*}}{R T_{f c}}\right)} e^{\left(\frac{\alpha n F \eta_{a c t}}{R T_{f c}}\right)} \quad\left[\mathrm{A} \mathrm{m}^{-2}\right]$

Thus, a performance improvement due to a greater exchange current density by increasing temperature is guaranteed if Eq. (17) is valid:

$\eta_{\text {act }}<\frac{\Delta G^{*}}{\alpha n F}$

Assuming a constant activation barrier $\Delta G^{*}$ of $66 \mathrm{~kJ} \mathrm{~mol}^{-1}$ for the ORR on platinum [22], this criteria is always fulfilled in the specific operating range of the studied fuel cell stack, as shown by the experimental data for activation polarization obtained by Husar et al. [21].

In conclusion, the improved reaction kinetics through a higher exchange current density is responsible for the majority of the voltage gain obtained by increasing the temperature. For instance, a positive temperature step of $2{ }^{\circ} \mathrm{C}$, as depicted in Figure 4, results in a theoretical stack voltage gain of $86 \mathrm{mV}$ only due to the increase of $i_{0}^{A E C D}$ by $17 \%$.

The thermal model of section 3.1 can now be linked to the electrochemical model in order to account for the temperature dependent reaction kinetics. Figure 6 shows the comparison of the simulated fuel cell temperature and stack voltage of the resulting "Model 1" to the experimental data discussed in section 2.2. As depicted in Figure 6(b), the simulated stack voltage of "Model 1" is higher than in the experiment which also involves a underestimation of the fuel cell temperature, shown in Figure 6(a). However, the thermal model dynamics match with the experimental data since $C_{p, f_{c}}$ was determined experimentally, as mentioned in section 3.1. According to Eq. (15) the voltage would monotonously increase with increasing temperature. However, the capability of improving performance by increasing temperature is limited due to drying of the cathode catalyst layer at elevated temperatures and the related loss of active sites [20], as shown in the experiment. The dynamic of the temperature related drying effect on fuel cell voltage is much slower than the gain in activity, which follows the temperature response of the fuel cell. Hence, in order to obtain a complete and valid voltage model of the fuel cell, the mesoscopic effects, such as hydration and dehydration effects of the catalyst layer, as described similarly by Wang et al. and Eikerling [3,4], have to be taken into account.

The Butler-Volmer approach used in this work therefore includes temperature and humidity dependent reaction kinetics. As described by Eq. (15) temperature variations directly affect the exchange current density, which is misleadingly neglected in most fuel cell system models. Moreover, the real electrochemical active area $A_{a c t}=a_{c} L_{c}$ is directly linked to the liquid water saturation in the CCL. Thus, the relative active catalyst area reduction during the temperature increase of the experiment shown in Figure 4 can be described by Eq. (18):

$A_{\text {act }}=A_{\text {ref }}\left(e^{K_{a c t}} s-1\right)$ if $0<s<s_{\text {opt }}$

If the fuel cell temperature is increased too much so that the liquid water saturation in the CCL drops close to 0 the fuel cell cannot provide the demanded power anymore which in turn causes the voltage to decrease in the experiment. The optimal saturation $s_{\text {opt }}$ is reached when the ionomer of the CCL is optimally humidified and proton transport to all other Pt particles that are not in direct contact with the ionomer is guaranteed by the presence of liquid water. If the liquid water saturation still increases the active area however does not change anymore.

The complete expression of the modeled fuel cell stack voltage finally results in: 
Since the composition and morphology of the CCL is unknown only a relative change in the active catalyst area can be determined based on an estimated reference active area. The dynamic of this active area reduction effect depends on the liquid water transport dynamics as explained in section 3.2. "Model 2" in Figure 6 shows the simulated voltage and temperature response to the steps in the fan flow rate which matches very well with the experimental data. The modeled dynamic of the catalyst drying effect, which is based on the dynamic of liquid water removal from the CCL, coincides well with the experiment.

The tuning parameters of the model are the gain of the active area reduction $K_{a c t}$ as well as the time constants for liquid water removal from the catalyst layer $K_{\text {evap }}$ and $K_{\text {sorp }}$. The latter was set to 0.003 , which is within the range of the experimentally determined water uptake dynamics of different catalyst layers from Kusoglu et al. [26]. The evaporation time constant is significantly faster than the sorption constant due to the high interfacial liquid to vapor surface area in the porous media of the GDL and the CL. The phase change model used in [17] and the respective set of parameters shows that the values for the phase change rates may change by more than two orders of magnitude. In this work $K_{\text {evap }}$ was set to $4.3 \times 10^{5} \mathrm{~s}^{-1}$, which is in the middle of the range presented by $\mathrm{Wu}$ et al. [17]. This makes the evaporation rate constant more sensitive to changes in temperature, however, the slow sorption dynamics cause a slow approach to steady-state. Finally $K_{a c t}$ reflects the impact of changes in liquid water saturation by the sum of evaporation, sorption, generation and diffusion on the active Pt surface area. This parameter was tuned with experimental data at $0.18 \mathrm{~A} \mathrm{~cm}^{-2}$ and set to 0.1 . The correction of the voltage model resulted also in the correct temperature simulation, as depicted in Figure 6(a). The lower voltage leads to greater heat generation due to the lower efficiency and thus to a higher fuel cell temperature.

The model validation against experimental data at a current density of $0.22 \mathrm{~A} \mathrm{~cm}^{-2}$ with a larger step size is shown in Figure 7. The model differs slightly from the experimental data, however gives a good overall representation of the voltage and temperature transients. Interestingly the larger temperature step of about 10 ${ }^{\circ} \mathrm{C}$ results in slower thermal system dynamics, compared to the $2{ }^{\circ} \mathrm{C}$ step in Figure 6. One possible reason could be the different cell temperatures within the stack from the endplates to the middle of the stack, since an average is used in this study. The faster estimated temperature evolution leads to a lower simulated peak voltage than in the experimental dataset. The most sensitive parameter is the initial state of humidification of the CL. Figure 7 shows that the system is actually less humidified at $40{ }^{\circ} \mathrm{C}$ than predicted by the model and is more sensitive to the decreasing liquid water content induced by the increase in temperature. For the control problem the initial state of humidification is always unknown after shutdown and restart of the system due to the open-cathode nature of the system and the very slow CL humidification dynamics without additional reactant humidification. The situation becomes worse after the system has not been operated for a long time. However, by comparing online simulation with the actual measurement data, the crucial parameters such as $s_{C L, 0}$ and $K_{a c t}$ can be identified.

Figure 8 shows experimental validation results at a current density of $0.13 \mathrm{~A} \mathrm{~cm}^{-2}$ while down-stepping the temperature (up-stepping the fan flow rate). As mentioned above, the overestimated temperature at around $1500 \mathrm{~s}$ and $2000 \mathrm{~s}$ may result from different cell temperatures within the stack compared to the assumed equal cells in this model. The higher temperature leads to larger voltage increase due to improved reaction kinetics at $1500 \mathrm{~s}$. However, the important dynamics of the voltage increase due to the increasing liquid water saturation in the CCL after the decrease in temperature at $1700 \mathrm{~s}$ is well represented, even if a constant offset exists.

Overall, the model is capable of good prediction of voltage and temperature transient of the open-cathode stack. The experimental validation has shown that the stack voltage can be predicted with less than $0.5 \%$ error. The stack temperature validation results in a maximum error of about $1{ }^{\circ} \mathrm{C}$. Both errors may be partially results of average experimental values calculated from the sum of 20 cells.

The validated model can now be used to develop appropriate control strategies for the performance optimization problem by temperature control.

\subsection{State-space representation}

Transforming the model into the state space representation, gives useful information for the controller design. The presented model consists of two dynamic states which are the fuel cell temperature $x_{1}=T_{f c}$ and 
the liquid water saturation in the CCL $x_{2}=s$. The load current $I$ and the cathode inlet air temperature $T_{a m b}$ can be considered as measurable, external perturbations $z_{1}$ and $z_{2}$, respectively. The control action $u$ of the system is the inlet air velocity $v_{\text {air }}$. As explained in section 3.1 the dynamics of the fan are fast enough to be neglected in this analysis. The output of the system $y$ is the activation overpotential $\eta_{\text {act }}$, which can be linked to the fuel cell voltage via Eq. (13). Thus, the state space representation of the model results in:

$\dot{x}_{1}=K_{1} z_{1} y+K_{1} z_{1}^{2}-K_{2} x_{1} u+K_{2} z_{2} u$

$\dot{x}_{2}=K_{3} z_{1}-K_{4} x_{2} f_{p}\left(x_{1}\right)-f_{d}\left(x_{2}\right)$

$y=K_{5} x_{1} f_{a}\left(x_{1}, x_{2}, z_{1}\right)$

The state equations show that the system is highly non-linear. First of all because the functions $f_{p}, f_{d}$ and $f_{a}$ are all non-linear functions. Secondly, the control action is multiplied by the state $x_{l}$. A problem for the control of the liquid water saturation in the CCL is that the only control action has no direct influence on the state $x_{2}$, only via $x_{1}$. The structure of Eqs. (20) and (21) shows that the system is control-affine.

\section{CONTROLLER PROPOSAL}

Since the global voltage optimization task is difficult even with the developed model, a first approach would be a model-free controller that considers only the input-output behavior of the system. Thus, the proposed controller for the optimization problem is a cascaded controller that consists of a local PI controller that regulates voltage of the cooling fan and an Extremum seeking algorithm that calculates the optimal temperature set point for the PI controller.

\subsection{Temperature controller}

The PI controller has been designed following the tuning rules of Ziegler and Nichols in the frequency domain [23] and iterative fine-tuning. The control law is shown in Eq. (23). The offset $e(t)$ is the difference of the temperature set point and the actual stack temperature. The applied proportional gain $K_{p}$ is 0.8 and the integrator time constant $T_{i}$ is 20 .

$u(t)=K_{p} e(t)+\frac{1}{T_{i}} \int_{0}^{t} e(\tau) d \tau$

As explained above, the temperature is controlled by the cooling fan, which is a DC electronic motor with an upper and lower voltage limit. When the control action excesses this limit, the feedback loop is broken and the system runs in open loop because the actuator remains saturated. In order to avoid a building up of the integral term, an anti-windup loop has to be integrated into the controller. The controller was implemented in Simulink and tested in combination with the developed thermal model of the fuel cell under different operating conditions, perturbations and set points. Figure 9 shows the performance of the temperature controller during a dynamic simulation period of $1000 \mathrm{~s}$ together with the evolution of the stack voltage, liquid water saturation and the cathode inlet air velocity. Band-limited noise based on experimental data is added to the temperature feedback of the simulation in order to account for measurement noise. The designed PI controller manages to control the temperature fast and properly after changes in the temperature set point as well as during perturbations in heat generation by changes in the stack current, as shown by Figure 9 . The third graph of Figure 9 shows upper and lower saturation of the input to the fuel cell system $v_{\text {air }}$ and the impact of measurement noise. The effects of water production and evaporation on the liquid water saturation after changes in current and temperature are shown by the middle graph of Figure 9. In the simulated temperature range stack voltage transients are dominated by the changes in the stack temperature due to the faster thermal dynamics compared to the slow CL humidification dynamics.

\subsection{Extremum seeking control for performance optimization}

As a first approach, a self-optimizing control algorithm is applied in this work in order to maximize the voltage output of the fuel cell by adaption of a previously unknown reference point. The main advantage of this technique is that no knowledge about the plant is required, since the regulation is based on the inputoutput behavior of the system only. Figure 10 shows the control scheme, similar to the published work of 
Krstic et al. [24]. The major difference is that cascade control is used in this work. Hence, temperature is controlled by the PI controller, while the Extremum seeking algorithm calculates the temperature set points. The basic idea of the Extremum seeking algorithm is to move the system around the neighborhood on both sides of a maximum by application of a slow periodic perturbation and analyzing the system's response [24]. The estimated gradient determines the sign and gain adaption of the control action. Thus, optimization is achieved by regulating the norm of the gradient at zero [25]. The main problem of this technique is that the perturbation frequency should be slow enough to consider the system to be static [25]. This, however, may result in convergence rates much slower than the system dynamics. Since the time constant of the thermal system is around $2 \mathrm{~min}$, as explained in section 2.2, depending on the operating conditions, the perturbation frequency was set to $0.008 \mathrm{~Hz}$.

The controller was implemented, adjusted and tested in Matlab/Simulink using the developed model. Figure 11 shows the simulation results at an operation point of $0.18 \mathrm{~A} \mathrm{~cm}^{-2}$. Band-limited noise based on experimental data is added to both the temperature and the voltage feedback of the simulation in order to account for measurement noise. The cut-off frequencies of the High-Pass filter $\omega_{H P}$ and the Low-Pass filter $\omega_{L P}$ were adjusted to $0.002 \mathrm{rad}^{-1}$ and $0.01 \mathrm{rad}^{-1}$, respectively. The amplitude $a$ of the perturbation signal was set to $0.3{ }^{\circ} \mathrm{C}$ and the integrator gain $K_{I}$ was adjusted to 0.015 . The simulation shows that the algorithm is capable to optimize the performance of the system within about $15 \mathrm{~min}$ and keeping the voltage at that point. At the beginning of the simulation the actuator saturates at the lower limit in order to heat up the fuel cell to the optimal temperature. Afterwards the PI controller regulates the stack temperature to the reference provided by the Extremum seeking controller.

However, the experimentally determined maximum, shown in Figure 5 was not reached. The reason is that due to the slow drying dynamics and the therefore necessary slow perturbation frequency which makes the algorithm slow, temperature overshoots during the peak seeking lead to severe drying and lead to instability problems, as explained in section 2.3. In order to avoid staying at elevated temperature for several minutes a low integrator gain was chosen. Afterwards the gain of the gradient estimation is too low to bring the system to the optimal performance within a reasonable time. Nevertheless, an operation point with improved performance is reached.

\section{IMPLEMENTATION AND TEST}

A Dynamic-link library (DLL) of the controller was created from the Simulink model, using the Matlab Real-time workshop, and implemented into the LabView data acquisition system of the test station. Tests with the controller were performed under the same operating conditions as the characterization experiments, presented in section 2. Figure 12 shows the experimental results of the operation with the designed controller at a current density of $0.18 \mathrm{~A} \mathrm{~cm}^{-2}$. Even though the maximum is reached, the controller does not manage to keep the system at this maximum voltage because of the very slow catalyst drying effect, which complicates the detection of a significant change in the gradient. Decreasing the frequency of the perturbation signal and readjusting the filters might solve this problem, however, this would make the system even slower. A bigger integrator gain could help as well, however this would cause a higher overshoot. Since the system dynamics are slow it would take even more time to reach steady-state. The greatest problem is still the slow accommodation of the voltage at a stationary operation point, even if the temperature is well controlled. Optimally the controller would have to start regulating the temperature before the actual voltage maximum is detected.

\section{CONCLUSIONS}

The experimental and theoretical analysis of temperature effects on system performance of an open-cathode fuel cell system shows the great importance of proper thermal management strategies. The temperature dependency of the exchange current density shows the most significant effect on performance. However, the improvement by increasing temperature is limited due to the decreasing liquid water content in the catalyst layer at elevated temperatures and the related loss of active sites.

The simulation results with the presented thermal and electrochemical models under operation with the designed Extremum seeking controller show promising results in terms of optimal temperature control. However, the experimental validation resulted in insufficient capability of the controller to stabilize the voltage at the detected maximum. This is a result of the slow system dynamics, especially the gradual voltage decay due to the temperature related drying of the catalyst layer. A possible solution for this problem 
is the use of a model-based controller in conjunction with the control-oriented model of the fuel cell system that accounts for the explained drying effect. Work is in progress in order to adopt the model for real-time control in a model-predictive controller. However, the robust performance improvement only by temperature control is still a challenging task. Incorporation of a second control action that has direct influence on the liquid water saturation in the CL will improve the controllability of the system.

\section{ACKNOWLEDGEMENTS}

The experimental work was performed at the Fuel Cells Laboratory of the Institut de Robòtica i Informàtica Industrial (CSIC-UPC, Barcelona). All experiments were only possible due to the laboratories' advanced equipment and proficient technical staff. This work is partially funded by the national project MICINN DPI2011-25649, as well as by the 7th Framework Programme of the European Commission in the context of the Fuel Cells and Hydrogen Joint Undertaking (FCH JU) through the project PUMA-MIND FP7 303419. The work of P. Puleston was supported by CONICET and UNLP (Argentina), as well as Marie Curie FP72011-IIF, ACRES (299767/911767) (EU). Finally, the authors highly appreciate the support of the LEICI and the UNLP in enabling a research stay of S. Strahl at the laboratory in La Plata.

\section{REFERENCES}

1. S. Strahl, A. Husar and M. Serra. (2011). Development and experimental validation of a dynamic thermal and water distribution model of an open cathode proton exchange membrane fuel cell. Journal of Power Sources, 196(9), 4251-4263.

2. Majsztrik, P. W., Satterfield, M. B., Bocarsly, A. B., Benziger, J. B. (2007). Water sorption, desorption and transport in Nafion membranes. Journal of Membrane Science, 301(1), 93-106.

3. Wang, Q., Eikerling, M., Song, D., Liu, Z. (2004). Structure and performance of different types of agglomerates in cathode catalyst layers of PEM fuel cells. Journal of Electroanalytical Chemistry, 573(1), 61-69.

4. Eikerling, M. (2006). Water Management in Cathode Catalyst Layers of PEM Fuel Cells A StructureBased Model. Journal of The Electrochemical Society, 153(3), E58-E70.

5. Bidoggia B, Knudsen SK (2013). Estimation of membrane hydration status for standby proton exchange membrane fuel cell systems by complex impedance measurement: Constant temperature stack characterization. International Journal of Hydrogen Energy, 38, 4054-4066.

6. Rodatz P, Büchi F, Onder C, Guzzella L. (2004). Operational aspects of a large PEFC stack under practical conditions. Journal of Power Sources 128(2), 208-217.

7. Mench, Matthew M., Emin Caglan Kumbur, T. Nejat Veziroglu. Polymer electrolyte fuel cell degradation. Academic Press, 2011.

8. Zhang G, Kandlikar SG. (2012). A critical review of cooling techniques in proton exchange membrane fuel cell stacks. International Journal of Hydrogen Energy, 37, 2412-2429.

9. C. Kunusch, P. Puleston, M. Mayosky, A. Husar. (2011). Control-Oriented Modeling and Experimental Validation of a PEMFC Generation System. IEEE Transactions on Energy Conversion, 26(3) 851-861.

10. Riascos, L. and Pereira, D. D. (2009). Optimal temperature control in PEM fuel cells. In Industrial Electronics. IECON'09. 35th Annual Conference of IEEE, 2778-2783.

11. Li X, Deng Z, Wei D, Xu C, Cao G. (2011). Novel variable structure control for the temperature of PEM fuel cell stack based on the dynamic thermal affine model, Energy Conversion and Management, $52,3265-3274$.

12. Zhang, J., Tang, Y., Song, C., Cheng, X., Zhang, J., \& Wang, H. (2007). PEM fuel cells operated at 0\% relative humidity in the temperature range of 23-120 C. Electrochimica Acta, 52(15), 5095-5101.

13. R. O'Hayre, S. Cha, W. Colella and F. B. Prinz. (2009) Fuel cell fundamentals. John Wiley \& Sons, Inc.

14. James Larminie and Andrew Dicks. (2003). Fuel cell systems explained. John Wiley \& Sons, Inc.

15. E. A. Müller and A. G. Stefanopoulou. (2005). Analysis, modeling, and validation for the thermal dynamics of a polymer electrolyte membrane fuel cell system. Excerpt from the third International Conference on Fuel Cell Science, Engineering and Technology, Ypsilanti, Michigan, USA, no. FUELCELL2005- 74050.

16. Pasaogullari, U., Wang, C. Y. (2004). Liquid water transport in gas diffusion layer of polymer electrolyte fuel cells. Journal of the Electrochemical Society, 151(3), A399-A406. 
17. Wu, H., Li, X., Berg, P. (2009). On the modeling of water transport in polymer electrolyte membrane fuel cells. Electrochimica Acta, 54(27), 6913-6927.

18. Husar, A., Higier, A., Liu, H. (2008). In situ measurements of water transfer due to different mechanisms in a proton exchange membrane fuel cell. Journal of Power Sources, 183(1), 240-246.

19. T. E. Springer, T. A. Zawodzinski and S. Goftesfeld. (1991). Polymer Electrolyte Fuel Cell Model. Journal of The Electrochemical Society, vol. 138, pages 2334-2342.

20. Ciureanu, M. (2004). Effects of Nafion dehydration in PEM fuel cells. Journal of Applied Electrochemistry, 34, 705-714.

21. A. Husar, S. Strahl and J. Riera. (2012). Experimental characterization methodology for the identification of voltage losses of PEMFC: Applied to an open cathode stack. International Journal of Hydrogen Energy, 37(8), 7309-7315.

22. Frano Barbir. (2005). PEM fuel cells: Theory and practice. Elsevier Academic Press.

23. Karl Johan Aström and Richard M. Murray. (2008). Feedback systems: An introduction for scientists and engineers. Princeton University Press.

24. Krstic, M. and Wang, H. (1997). Design and Stability Analysis of Extremum Seeking Feedback for General Nonlinear Systems. Proceedings of the 36th Conference on Decision \& Control San Diego, California USA, 1743-1748.

25. Chioua, M., Srinivasan, B., Guay, M., Perrier, M. (2007). Solution of Perturbation-Based Extremum Seeking Methods on the Excitation Frequency. The Canadian Journal of Chemical Engineering, vol. 85, 447-453.

26. Kusoglu, A., Kwong, A., Clark, K. T., Gunterman, H. P. Weber, A. Z. (2012). Water Uptake of FuelCell Catalyst Layers. Journal of The Electrochemical Society, 159(9), F530-F535.

\section{FIGURES}

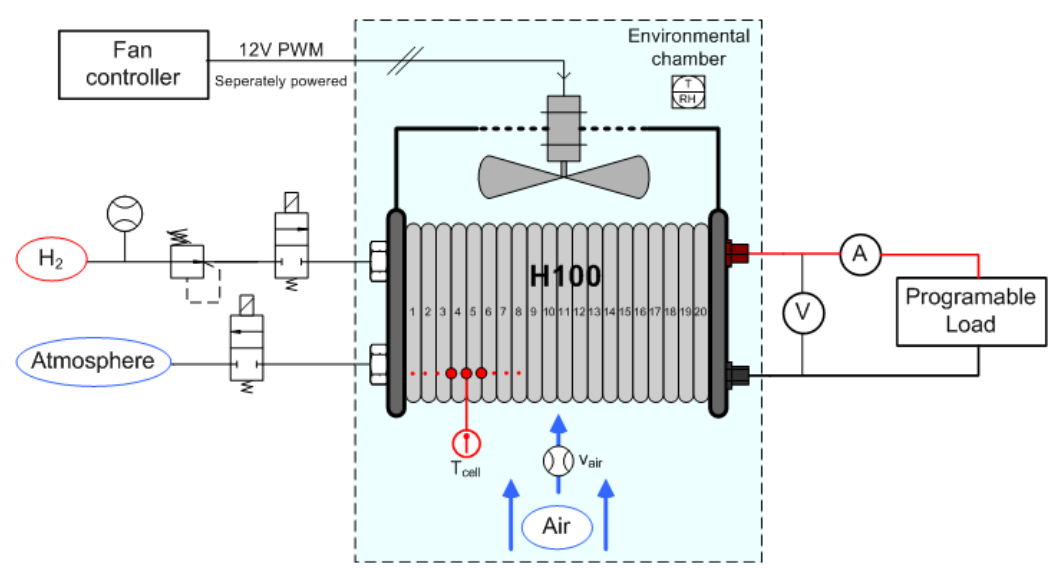

Figure 1. Schematic of the H100 fuel cell system installed in the laboratory test station 


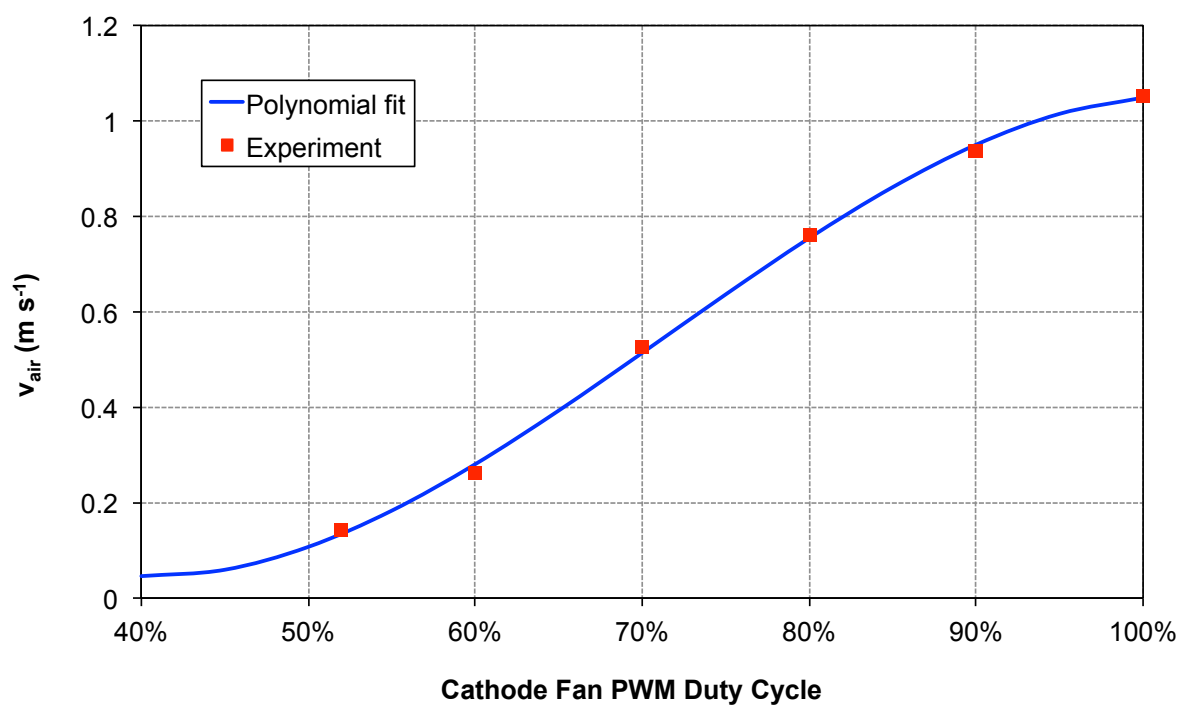

Figure 2. Relation between the cathode inlet air velocity and the PWM duty cycle
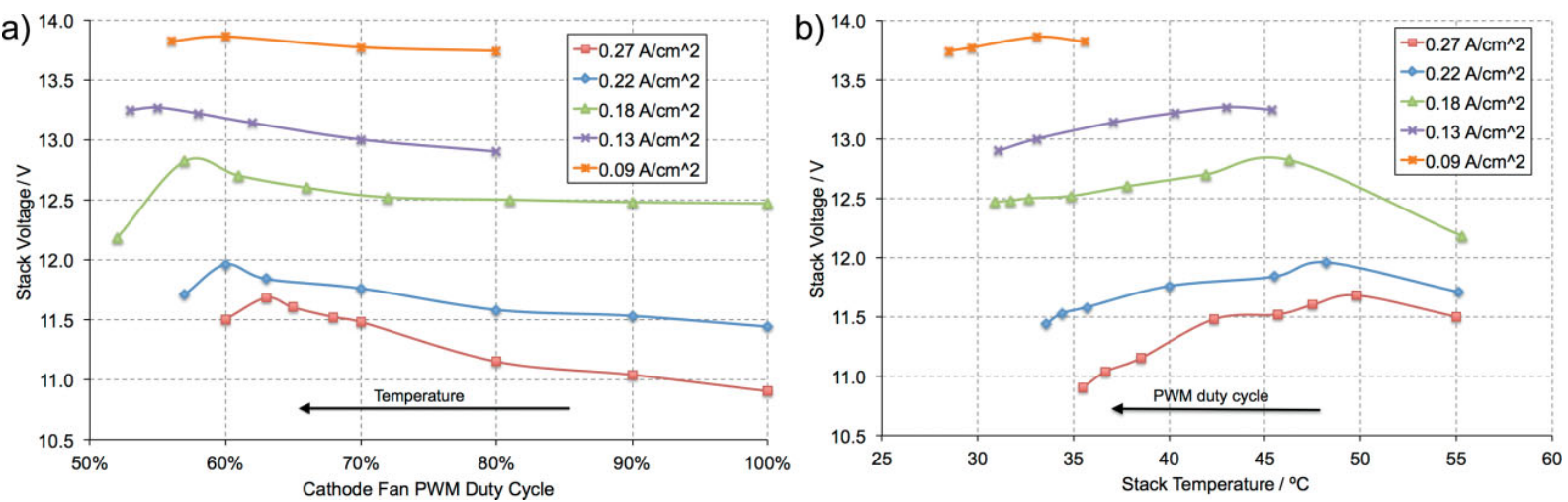

Figure 3. PWM duty cycle (a) and stack temperature (b) mapping against stack voltage
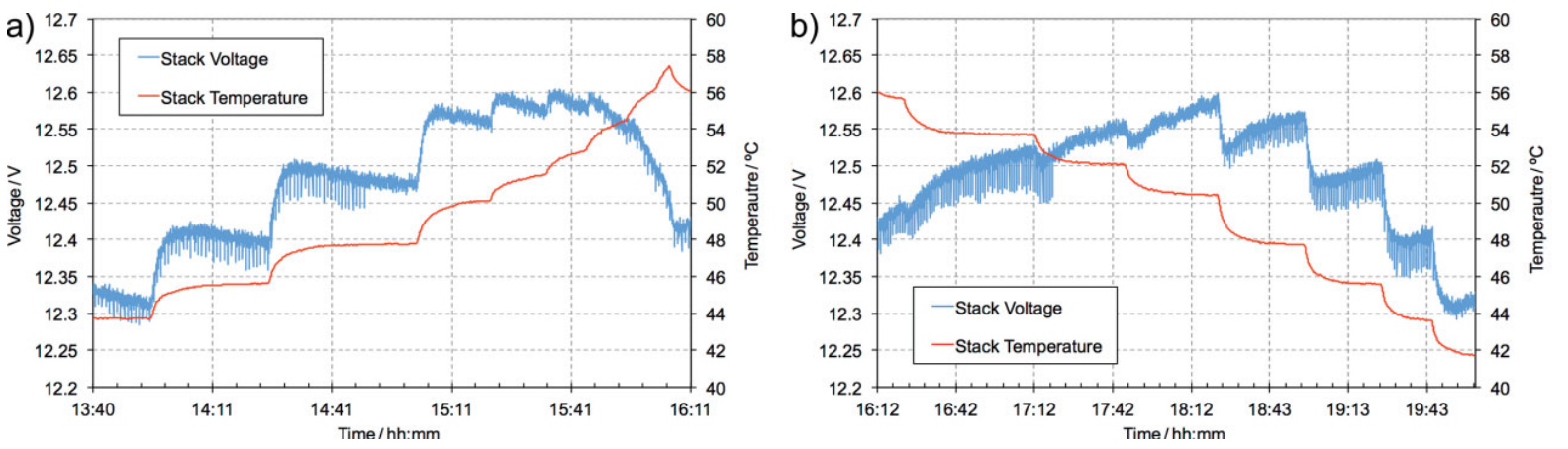

Figure 4. Stack temperature and voltage over time during down-stepping (a) and up-stepping (b) of fan PWM duty cycle at a constant current density of $0.18 \mathrm{~A} \mathrm{~cm}^{-2}$ 

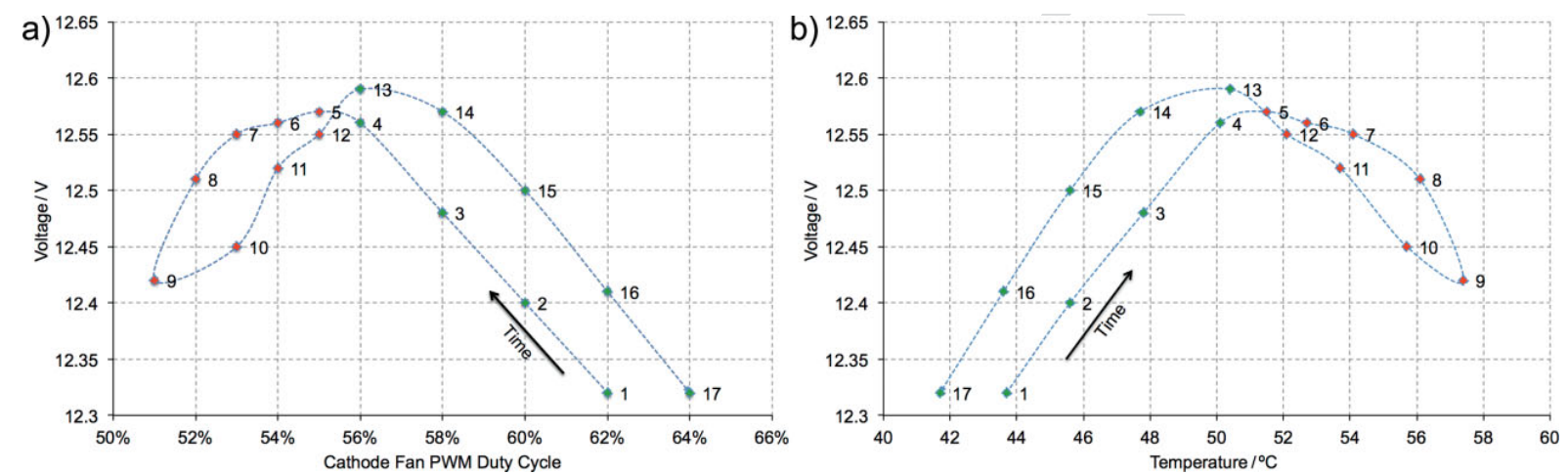

Figure 5. Stack voltage trajectory as a function PWM duty cycle (a) and stack temperature (b) at $0.18 \mathrm{~A} \mathrm{~cm}^{-2}$. Stable points are marked in green, unstable points in red.
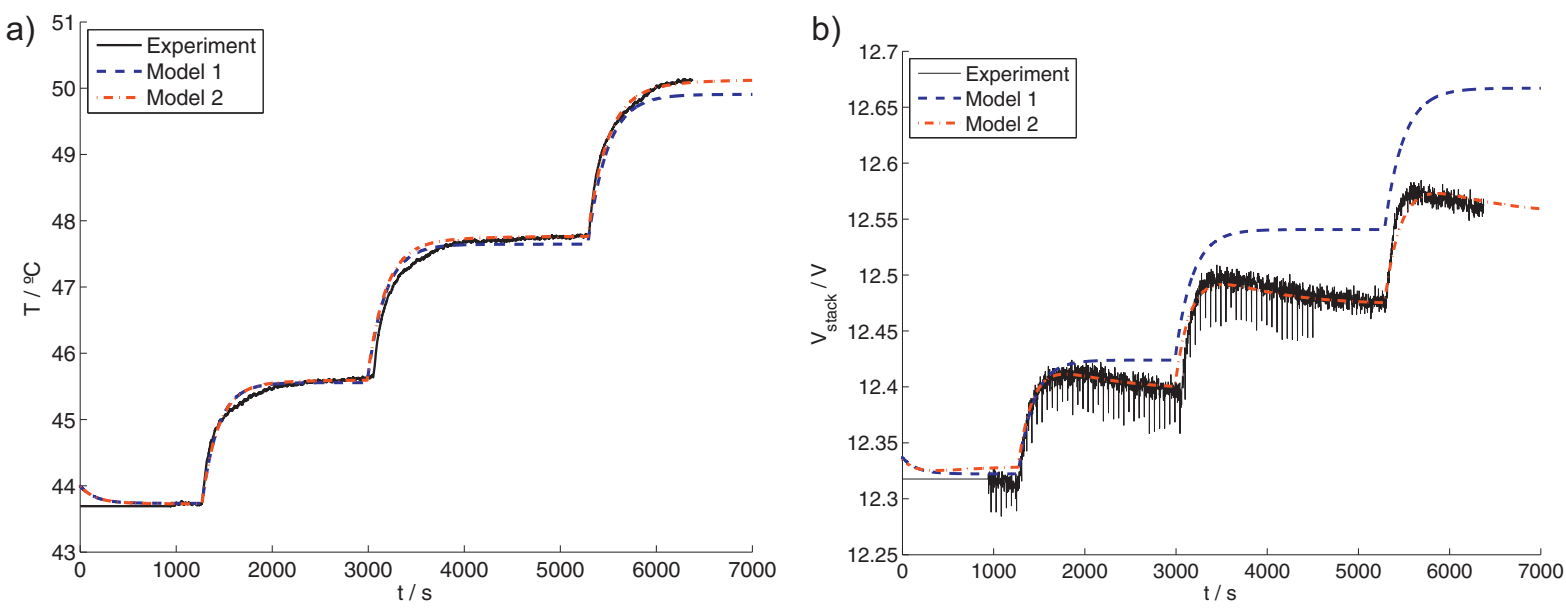

Figure 6. Comparison of the simulated temperature (a) and voltage (b) responses with the experimental data analyzed in section 2.2 at a current density of $0.18 \mathrm{~A} \mathrm{~cm}^{-2}$. Model 1 accounts only for the direct effect of temperature on the apparent exchange current density. Model 2 includes as well the variation of the active catalyst area.
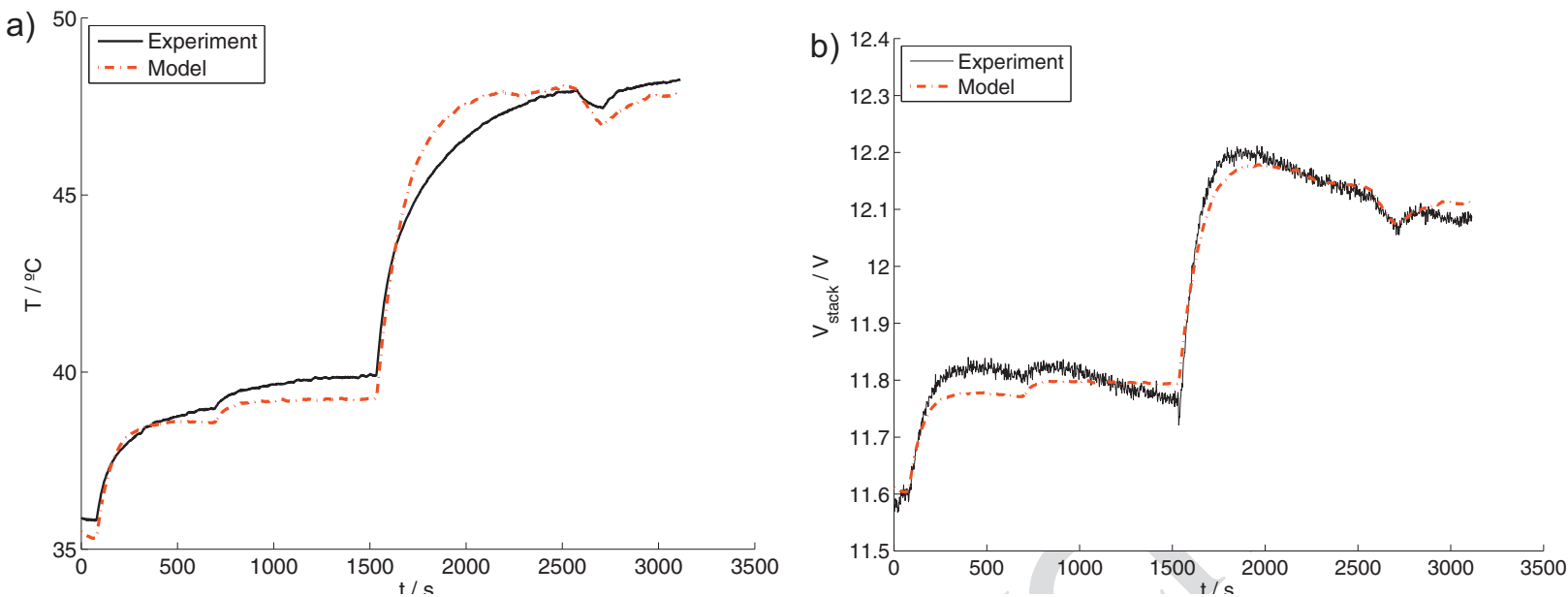

Figure 7. Comparison of the simulated temperature (a) and voltage (b) responses with the experimental data at a current density of $0.22 \mathrm{~A} \mathrm{~cm}^{-2}$. 

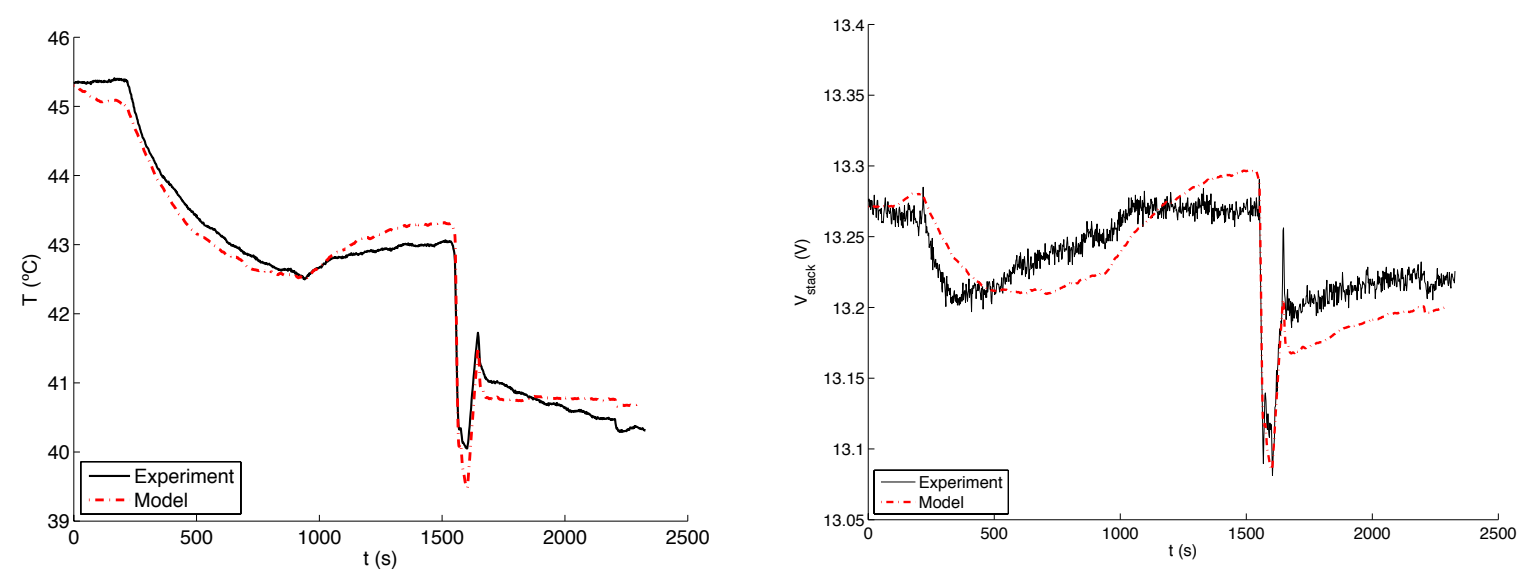

Figure 8. Comparison of the simulated temperature (a) and voltage (b) responses with the experimental data at a current density of $0.13 \mathrm{~A} \mathrm{~cm}^{-2}$.
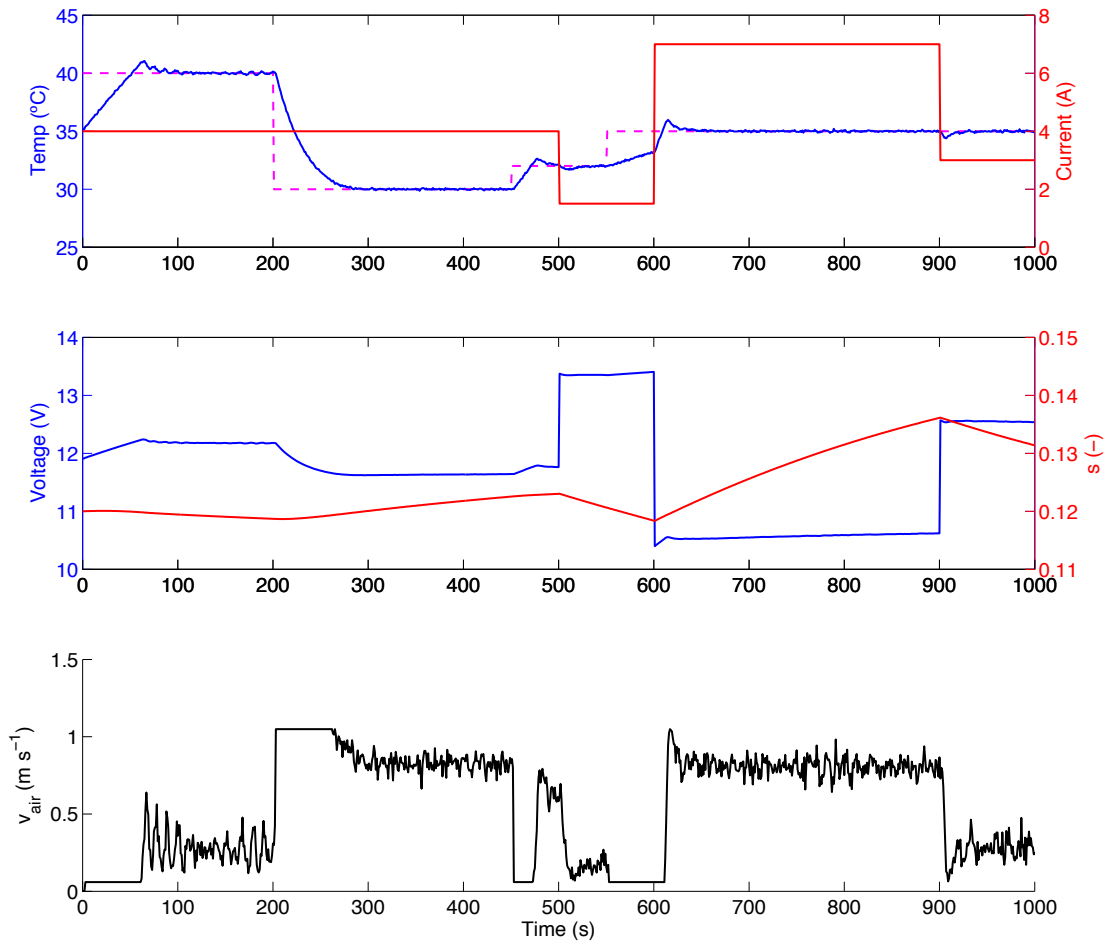

Figure 9. Temperature controller simulation results 


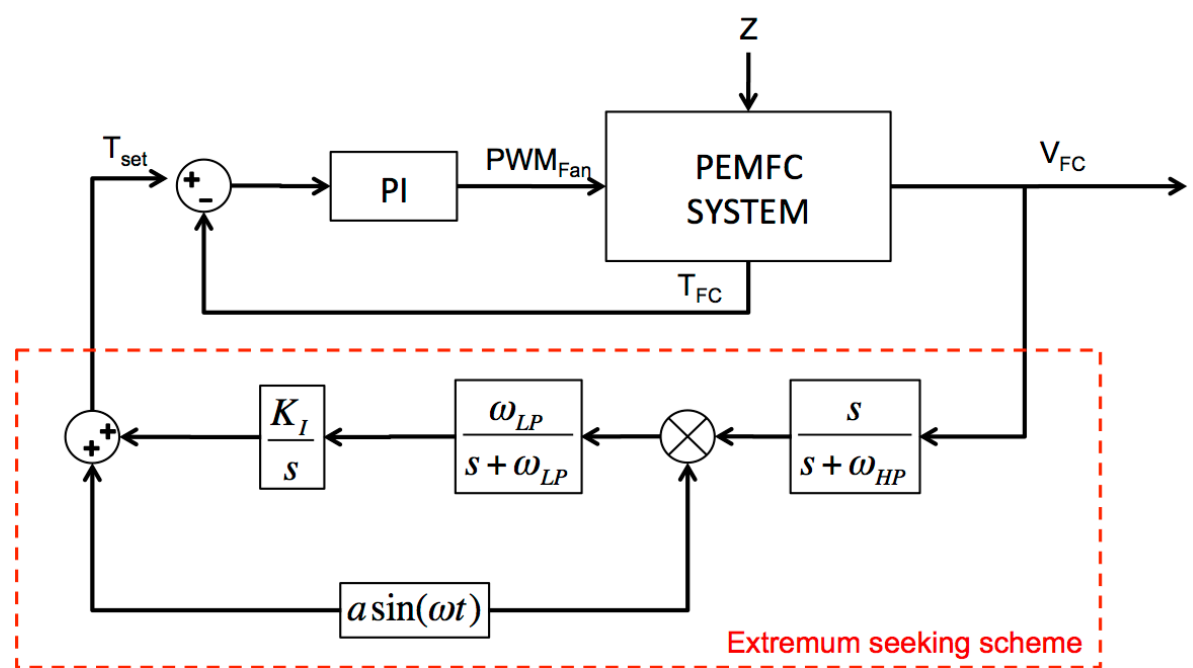

Figure 10. Control scheme
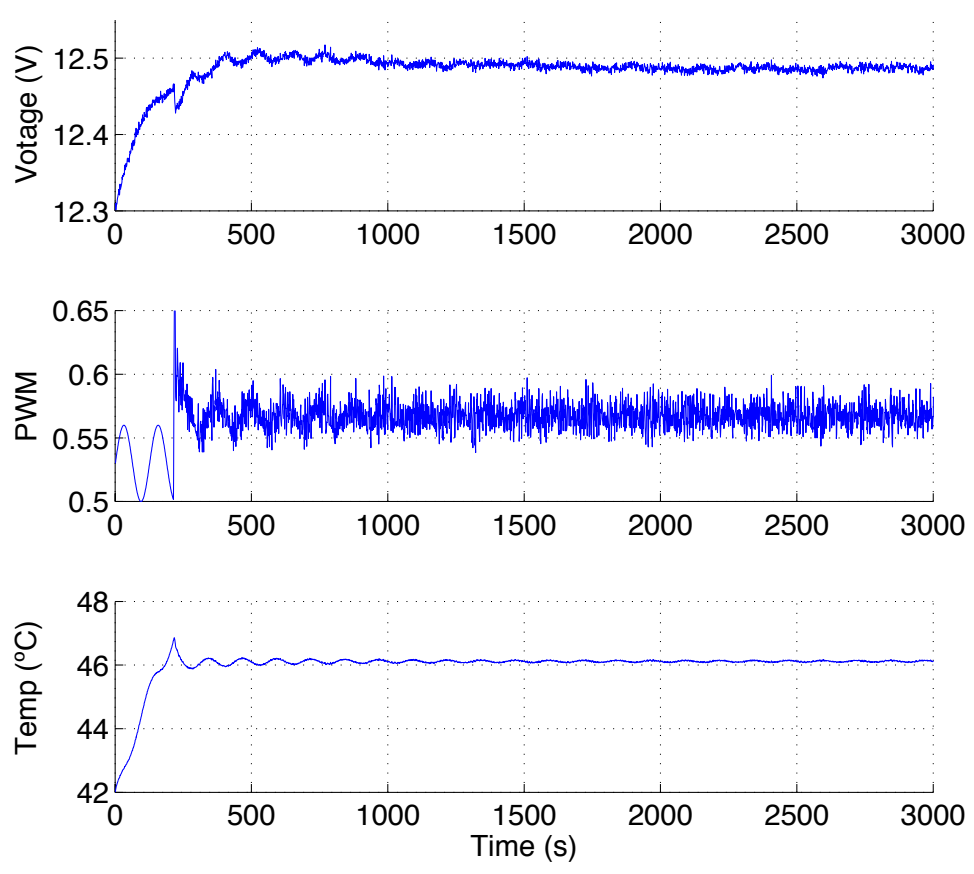

Figure 11. Simulation results at a current density of $0.18 \mathrm{~A} \mathrm{~cm}^{-2}$ 


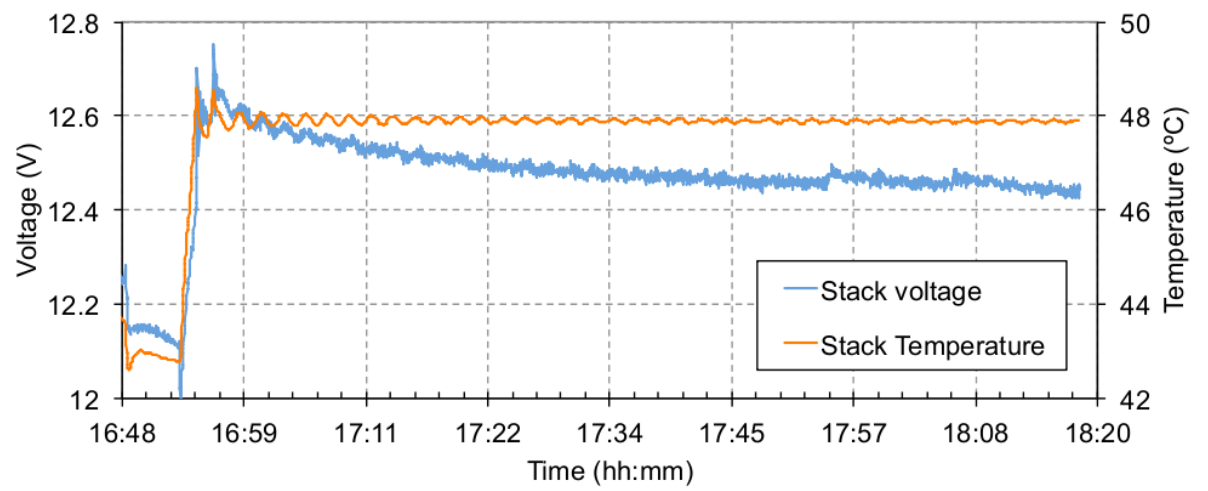

Figure 12. Experimental controller validation at a current density of $0.18 \mathrm{~A} \mathrm{~cm}^{-2}$ 